\title{
Survival Rate of Oral Bacteria on Toothbrush and Miswak Stick
}

\author{
Ismail Abbas Darout, Husham Elraih Homeida \\ Department of Preventive Dental Sciences, College of Dentistry, Jazan University, Jazan, Kingdom of Saudi Arabia
}

Email address:

idarout1959@gmail.com (I. A. Darout)

${ }^{*}$ Corresponding author

To cite this article:

Ismail Abbas Darout, Husham Elraih Homeida. Survival Rate of Oral Bacteria on Toothbrush and Miswak Stick. American Journal of Health Research. Vol. 4, No. 5, 2016, pp. 134-137. doi: 10.11648/j.ajhr.20160405.14

Received: August 28, 2016; Accepted: September 10, 2016; Published: September 29, 2016

\begin{abstract}
Introduction: Oral hygiene aids including toothbrushes if not rinsed in a proper disinfectant can affect oral bacterial translocation and re-infection of the oral cavity due contamination. Aim of the study: The aim of this study was to investigate the survival rate of total oral bacteria on toothbrush and miswak. Material and methods: Totally, 12young individuals with age range $22-28$ years and with 20 more remaining teeth in the oral cavity participated in this study. These individuals were asked to brush one side of their mouth with miswak stick and the other side with a nylon tooth brush (Orange toothbrush No: 106A China). 6 bristles from a tuft of each toothbrush and equivalent amount of fibers from each miswak stick were cut immediately after brushing for $2 \mathrm{~min}$ and serially diluted in anutrient broth. The bacterial suspension was inculcated in agar plates and incubated for overnight. The used toothbrushes and miswak sticks were stored in sterile containers at room temperature and the experiment was then repeated after 24 hours of storage. The survival rates of oral bacteria were then calculated by comparing the total bacterial counts at day one and 24 hours after storage. Results: Miswak sticks harbored an average of 845.6 total oral bacterial counts and 523.7 the toothbrush respectively at a day one. After 24 hours of storage, toothbrush harbors statistically significant $p<0.05$ more total bacterial counts as compared with miswak stick. Conclusion: The total oral bacterial survival rate on miswak was significantly reduced as compared with a toothbrush, thus the use of miswak after 24 hours can limits the risk for oral bacterial contamination and translocation. This is the first in vivo study which shows bacterial survival rate on miswak.
\end{abstract}

Keywords: Bacterial Carriage, Miswak, Toothbrush, Survival Rate of Bacteria

\section{Introduction}

The 1999 Consensus Statement on Oral Hygiene has concluded that dental plaque biofilm a primary etiological agent for dental caries, gingivitis and periodontitis; that its regular cleaning and removal on daily base is recommended for prevention or reduction of these diseases; that miswak chewing sticks may have a role in the promotion of oral hygiene; and that assessment of the effectiveness of miswak chewing sticks requires further research[1].Thus, the mechanical oral hygiene methods are reliable means of controlling plaque biofilm, provided cleaning and brushing are sufficiently thorough and performed at regular intervals.

Toothbrush after brushing has shown to be heavily contaminated with plaque biofilm. However, depending upon where we keep toothbrushes after use, the toothbrush can serve as a source for reintroduction of oral bacteria into the mouth [2]. Different microorganisms from storage environments can also be involved, which include enteric bacteria via aerosol near toilet flushing or from contaminated containers or fingers.

It has been recommended that toothbrushes after use should be rinsed in disinfectants like Chlorhexidine gluconate $0.2 \%$ before storage [3]. Later,it has been shown that drying of toothbrush in sunlight, table salt to absorb their moisture and/or keeping the brush in a closed container with preparation containing formaldehyde for its disinfection is important procedures $[4,5]$. 
Miswak chewing sticks are used for tooth cleaning by many communities around the world. Reasons for continuing the use of miswak include low cost, availability and or tradition [6]. Moreover, it has been indicated that miswak released pleasant chemicals during chewing and cleaning. A large body of miswak research has not highlighted the mechanism of action of miswak. However, it has mentioned that the chemical components released during cleaning caused oral health promotion and disease prevention. Potential of miswak chemical components releasing during chewing may reduce potential of contamination of miswak [7]. It has been postulated that thiocyanate leaching during cleaning can activate salivary peroxidase thiocyanate hydrogen peroxide antimicrobial system [7].

The cleaning efficacy of miswak is shown to be comparable with that of manual toothbrush or indicated plaque scores to be significantly lower following the use of miswak as compared with the manual toothbrush used without toothpaste. In a controlled study, Kenyan school children brushed their teeth for $5 \mathrm{~min}$ at a time using chewing sticks with or without toothpaste [8]. Compared with the baseline data, the brushing under supervision resulted in reduction of plaque deposit proration [9]. Therefore, toothpaste used along with toothbrush did not seem to enhance plaque removal efficiency of the toothbrush.

Toothbrushing generally has only one mode of action, the mechanical removal of dental plaque. However, toothbrushes are also used as a vehicle for supragingival delivery of antiplaque agents and fluoride incorporated into different toothpastes. The use of toothpaste is such a complementary part of toothbrushing behavior that it cannot be ignored [10].Thus, toothbrushing with toothpaste was arguably the most common form of tooth cleaning practiced by individuals in developed countries. Chewing sticks are often used as the sole cleansing agent in the developing countries. The Consensus Statement on Oral Hygiene states that tooth brushing and other mechanical methods, including miswak chewing sticks are the most reliable means of controlling plaque, provided that the cleaning is sufficiently through and performed in regular base. However, since most studies on miswak lack specific details concerning the oral bacterial contamination it has been difficult to assess the effect of miswak chewing sticks carriage of oral bacteria during storage. The aim of this study was to investigate the survival rate of oral bacteria on toothbrush and miswak sticks using bacterial culture procedures.

\section{Materials and Methods}

At the dental clinic of the college of dentistry, University of Jazan,12 young individuals with age range 22-28 years and with 20 more remaining teeth in the oral cavity were asked to brush one side of their mouth with miswak sticks and the other side with a nylon toothbrushes (Orange toothbrush No:106A China). Both oral hygiene devices were then not rinsed with water, and carried in sterilized containers to the laboratory of oral microbiology at the college of dentistry. 6 bristles of a tuft from each toothbrush and equivalent amount of fibers from each miswak stick were cut immediately after brushing for 2 min and placed in sterile nutrient broth (Oxoid U.K) which composed of 1 gram lablemco, 2gram yeast extract, 5 gram peptone and 5 gram sodium chloride.The medium was prepared by dissolving thirteen grams of dehydrated nutrient broth in one litter of distilled water, mixed up well, the $\mathrm{pH}$ was adjusted to 7.4 and the medium was distributed in $5 \mathrm{ml}$ amount into test tubes and sterilized by autoclaving at $121^{\circ} \mathrm{C}$ for 15 minutes. Following serial dilution, the bacterial suspension was used to inculcate nutrient agar (Oxoid U.K)plates for counting of the total bacteria colony forming units. The medium is composes of 1gram lab-lemco, 2gram yeast extract, 5 gram sodium chloride, 5gram peptone and 15 gram agar. It was prepared by adding 28gram of dehydrated nutrient agar to one liter of distilled water, and steamed to dissolve completely. The $\mathrm{pH}$ was adjusted to 7.54 and the medium was sterilized at $121^{\circ} \mathrm{C}$ for 15 minute, then aseptically poured into sterile plates (in $20 \mathrm{ml}$ amounts)or distilled in $5 \mathrm{ml}$ amount into sterile screwcapped bottles and allowed to set in slop position. The used brushes and miswak sticks were stored in sterile containers at room temperature for 24 hours and the same experiment was then repeated. Survival rates were calculated by comparing counts of colony forming units at day one and 24 hours storage. Boiled miswak stick for 2 hours was used as a control.

\section{Results}

At a day one, miswak harbored more total oral bacteria counts as compared with toothbrush with average total oral bacteria counts, colony forming units (CFU) 845.6 and 523.7 for toothbrush, respectively at $1 / 10$ concentrations. Table 1 shows average numbers of total oral bacterial counts on toothbrush and miswak according to serial dilutions at day one after brushing, this table shows the 3 experiments of both samples. After 24 hours storage toothbrush harbors significantly more total bacterial counts $195.3 \mathrm{CFU}$ and 1.5 CFU for miswak respectively at $1 / 10$ concentrations. Table 2 shows average numbers of total oral bacterial counts on toothbrush and miswak according to serial dilutions after 24 hours of storage. When we used boiled miswakas a control and toothbrush the results at a day one show that toothbrush harbored less total oral bacteria counts as compared with boiled miswak with average total bacteria counts 883.4 and 559.1 for the toothbrush, respectively at $1 / 10$ concentrations. Table 3 shows average numbers of total oral bacterial counts on toothbrush and boiled miswak according to serial dilutions at day one after brushing, this table shows the 3 experiments of both samples. When we used a control, boiled miswak and toothbrush the results after 24 hours storage show that toothbrush harbored average $648.5 \mathrm{CFU}$ less than boiled miswak sticks 1061.4 respectively at $1 / 10$ concentrations. Table 4 Average numbers of total oral bacterial counts on toothbrush and boiled miswak stick according to serial dilutions after 24 hours storage (control). 
Table 1. Average numbers of total oral bacterial counts on toothbrush and miswak according to serial dilutions at day one after brushing.

\begin{tabular}{llllllllll}
\hline Toothbrush & \multicolumn{10}{c}{ Miswak } \\
\hline Dilutions & $1 / 10$ & $1 / 100$ & $1 / 1000$ & $1 / 10000$ & Dilutions & $1 / 10$ & $1 / 100$ & $1 / 1000$ & $1 / 10000$ \\
Expriment1 & 343.6 & 20.1 & 1.7 & 0.3 & Expriment1 & 730.6 & 26.7 & 3 & 0.0 \\
Expriment2 & 805.6 & 61.3 & 26.6 & 3.3 & Expriment2 & 1021 & 711 & 153.3 & 34.3 \\
Expriment3 & 422 & 54.5 & 3.6 & 1 & Expriment3 & 785.3 & 253 & 27 & 3.6 \\
\hline
\end{tabular}

The $p$-value is .064144 . The result is not significant at $p<.05$.

Table 2. Average numbers of total oral bacterial counts on toothbrush and miswak according to serial dilutions after 24 hours of storage.

\begin{tabular}{llllllllll}
\hline Toothbrush & \multicolumn{10}{c}{ Miswak } \\
\hline Dilutions & $1 / 10$ & $1 / 100$ & $1 / 1000$ & $1 / 10000$ & Dilutions & $1 / 10$ & $1 / 100$ & $1 / 1000$ & $1 / 10000$ \\
Expriment1 & 124.6 & 6 & 0.7 & 0.0 & Expriment1 & 1.7 & 0.0 & 0.0 & 0.0 \\
Expriment2 & 282.6 & 42 & 4 & 0.0 & Expriment2 & 1.3 & 0.0 & 0.0 & 0.0 \\
Expriment3 & 178.6 & 8 & 0.0 & 0.0 & Expriment3 & 1.6 & 0.0 & 0.0 & 0.0 \\
\hline
\end{tabular}

The $p$-value is .006968 . The result is significant at $p<.05$.

Table 3. Average numbers of total oral bacterial counts on toothbrush and boiled miswak stick according to serial dilutions at day one after brushing (control).

\begin{tabular}{llllllllll}
\hline Toothbrush & \multicolumn{10}{c}{ Miswak } \\
\hline Dilutions & $1 / 10$ & $1 / 100$ & $1 / 1000$ & $1 / 10000$ & Dilutions & $1 / 10$ & $1 / 100$ & $1 / 1000$ & $1 / 10000$ \\
Expriment1 & 543.6 & 18.1 & 1.6 & 0.3 & Expriment1 & 863.3 & 434.6 & 82.6 & 18.6 \\
Expriment2 & 705.6 & 41.3 & 20.6 & 3.3 & Expriment2 & 965.3 & 508.3 & 92.5 & 20.7 \\
Expriment3 & 428 & 50.5 & 2.6 & 1 & Expriment3 & 821.6 & 435.3 & 77.3 & 16.3 \\
\hline
\end{tabular}

The $p$-value is .011801. The result is significant at $p<.05$.

Table 4. Average numbers of total oral bacterial counts on toothbrush and boiled miswak stick according to serial dilutions after 24 hours storage (control).

\begin{tabular}{llllllllll}
\hline Toothbrush & & \multicolumn{1}{c}{ Miswak } \\
\hline Dilutions & $1 / 10$ & $1 / 100$ & $1 / 1000$ & $1 / 10000$ & Dilutions & $1 / 10$ & $1 / 100$ & $1 / 1000$ & $1 / 10000$ \\
Expriment1 & 696.6 & 14.3 & 0.0 & 0.0 & Expriment1 & 1075 & 475.3 & 40.1 & 21.3 \\
Expriment2 & 718.3 & 6.6 & 0.0 & 0.0 & Expriment2 & 1120 & 325.6 & 44.5 & 28.1 \\
Expriment3 & 530.5 & 4.1 & 0.0 & 0.0 & Expriment3 & 989 & 299.3 & 56.3 & 24.6 \\
\hline
\end{tabular}

The $\mathrm{p}$-value is .002141 . The result is significant at $\mathrm{p}<.05$.

\section{Discussion}

Dental caries and periodontal disease are contagious diseases that can be transmitted through contaminated instruments [11].The reuse of toothbrush during sometime of a day for tooth cleaning and/or tongue cleansing can be a source of contamination and translocation of plaque bacteria. Carless storage of this device can increase its bacterial carriage during storage because of bacterial growth which can increase the chance of infection and intraoral location after use [12, 13, 14].

The results obtained in this study showed that there were many types of microorganism's colony forming units that were grown on the toothbrush and miswak. The results show that at day one toothbrush harbored less colony forming units as compared with miswak, this can be explained by that the bristles of toothbrush are smoother than the fibers of miswak which harbored more oral bacteria on the rough surfaces. However, this result has been changed after storage of booth devices for 24 hours. Thus, statistically significant high numbers of colony forming were grown on toothbrush as compared with miswak after storage.

The growth of total bacteria on toothbrush is in agreement with other studies $[12,13]$. However, the total counts found on toothbrush bristles and miswak fibers were dislocated from plaque biofilm during brushing; moreover, other types of microorganisms might also grown as total bacterial colony forming units. Previously, it has been demonstrated that streptococci are the largest numbers of microorganisms found on the toothbrushes that were kept in air for 24 hours, this group represents the most common hygienic measure that is undertaken by the majority of individuals with their toothbrushes without immersing in any antimicrobial solution, and the same results were seen in previous studies [11]. As shown in our results, there was a significant reduction in the mean number of total colony forming units in miswak as compared with toothbrush.The finding of this study is with agreement of our previous observation (Darout et al.2014 unpublished work).

Some in vitro studies have shown that miswak extracts inhibited growth of various oral aerobic and anaerobeic bacteria as well as Candida albicans[15]. Inhibition of in vitro plaque formation, growth and acid production of various cariogenic bacteria by such extracts has also been demonstrated. In addition, aqueous extracts of miswak bark, pulp as well as whole miswak were effective against various bacteria including Streptococcus mutans [16]. Miswak antimicrobial components may be released during chewing 
which has growth inhibitory effect of many species from dental plaque $[17,18]$. Our study shows that miswak chewing stick reduces the mean number of colony forming units during storage as compared with toothbrush. It has been shown that there was no noticeable difference in antimicrobial effect between fresh and one-month-old miswak [16]. Miswak contains many chemical components which can be activated while in the mouth by saliva, for instance, $\mathrm{Cl}^{-}$leaching into saliva from miswak may mediate the innate host defense systems in human saliva. $\mathrm{Cl}^{-}, \mathrm{I}^{-}$and $\mathrm{SCN}^{-}$(pseudohalides) are substrates for salivary peroxidase and/or the myeloperoxidase hydrogen peroxide antimicrobial system. The peroxidase-hydrogen-peroxide-chloride system is a part of the innate host defense that is mediated by polymorphonuclear leukocytes in humans [18]. It has been shown that the latter system was more bactericidal against Aggregatibacter actinomycetemcomitans than with the myeloperoxidase-thiocyanate and hydrogen peroxide system. Recently, it has been indicated that the oxidation product of lactoperoxidase and myloperoxidase with $\mathrm{I}^{-}$and/or $\mathrm{Cl}^{-}$was bactericidal against Porphyromonas gingivalis, Fusobacterium nucleatum and Streptococcus mutans [19]. The lower levels of Prevotella intermedia and Fusobacterium nucleatum in the miswak users may be attributed to its $\mathrm{Cl}^{-}$ and $\mathrm{SCN}^{-}$content. Oral hygiene aids including toothbrush if not stored in a proper disinfectant can affect oral bacterial translocation andreinfection of the oral, thus the bacterial survival rate on miswak was significantly reduced as compared with a toothbrush, and therefore the use of miswak after 24 hours can limits the risk for oral bacterial contamination and translocation. The use of more advanced bacterial detection technology as DNA-DNA hybridization methods will be more suitable to study the oral bacterial counts on toothbrush and miswak sticks especially after storage for 24 hours.

\section{Conclusion}

Oral hygiene aids including toothbrushes if not rinsed in a proper disinfectant can affect oral bacterial translocation andre-infection of the oral cavity due contamination. Oral microorganisms on toothbrushes can grow and increase in number after 24 hours. Our study results indicated that, the total oral bacterial survival rate on miswak was significantly reduced as compared with a toothbrush, thus the use of miswak after 24 hours can limit the risk for oral bacterial contamination and translocation. This is the first in vivo study which shows bacterial survival rate on miswak.

\section{References}

[1] Loe $\mathrm{H}$. Oral hygiene in the prevention of caries and periodontal disease. Int Dent J 2000; 50: 129-139.

[2] Mehta A, Sequeira PS, Bhat G. Bacterial contamination and decontamination of toothbrushes after use. N Y State Dent J. 2007; 73:20-2.

[3] Sogi SH, Subbareddy VV, Kiran SN.Contamination of toothbrush at different time intervals and effectiveness of various disinfecting solutions in reducing the contamination of toothbrush. J Indian Soc Pedod Prev Dent. 2002; 20:81-5.

[4] Ankola AV, Hebbal M, Eshwar S.How clean is the toothbrush that cleans your tooth?Int J Dent Hyg. 2009; 7:237-40.

[5] Bélanger-Giguère K, Giguère S, Bélanger M.Disinfection of toothbrushes contaminated with Streptococcus mutans. Am J Dent. 2011 Jun; 24:155-8.

[6] Sote EO. The relative effectiveness of chewing sticks and toothbrush on plaque removal. African Dent J 1987;1:48-53.

[7] Ismail A. Darout. Review on chemical and biologically active components of the toothbrush tree (salvadora persica) EJ PM R 2015,2(6): 12-17.

[8] Olsson B. Efficiency of traditional chewing sticks in oral hygiene programs among Ethiopian schoolchildren. Community Dent Oral Epidemiol1978; 6:105-109.

[9] Norton MR, Addy M. Chewing sticks versus toothbrushes in West Africa. A pilot study.ClinPrev Dent 1989; 11:11-13.

[10] Ashley P. Toothbrushing: why, when and how? Dent Update 2001; 28: 36-40.

[11] Meier S, Collier C, Scaletta MG, Stephen J, Kimbrough R, Kettering JD. An in vitro investigation of the efficacy of CPC for use in toothbrush decontamination. J Dent Hyg. 1996; 70.

[12] Neal PR, Rippin JW. The efficacy of a toothbrush disinfectant spray- an in vitro study.J Dent. 2003; 31: 153-157.

[13] Braz Dent J. 2003; 14(1): 58- 62. 26. Srinivusan M, Eapen BR, Bhas G, Kumar C. Efficacy of chlorhexidine as an oral antiseptic-An in vivo study of 20 patients. Middle East $\mathrm{J}$ Family Medicine. 2006; 3(5): 22-32. 27.

[14] Wetzel WE, Schaumburg C,Ansari F, Kroger T, Sziegoleit A. Microbial contamination of toothbrushes with different principles of filament anchoring. J Am Dent Assoc. 2005; 136(6): 758-765.

[15] Al lafi T, Ababneh H. The effect of the extract of the miswak (chewing sticks) used in Jordan and the Middle East on oral bacteria. Int Dent J 1995; 45:218-22.

[16] Almas $\mathrm{K}$, al-Bagieh $\mathrm{NH}$, Akpata ES. In vitro antibacterial effect of freshly cut and 1-month-old Miswak extracts. Biomed Letters 1997; 56:145-9.

[17] Darout IA, Skaug N. Salvadora persica as an external source for activation of the salivry peroxidase-thiocyanate and hydrogen peroxide system. Scand JImmunol 1997;45:566.

[18] $\mathrm{Xu} \mathrm{J}, \mathrm{Xu} \mathrm{X}$, Verstraete W. The antimicrobial effect and chemical reactions of acidified nitrite under conditions simulating the stomach. J Applied Microbiol 2001; 90:523-9.

[19] Tenovuo J, Mansson-Raheamtulla B, Pruitt KM, Arnold R. Inhibition of dental plaque acid production by the salivary lactoperoxidase antimicrobial system. Infect Immun 1981; 34:208-12. 